\title{
Reactive oxygen species in BCR-ABL1-expressing cells - relevance to chronic myeloid leukemia
}

\author{
Joanna Antoszewska-Smith¹, Elzbieta Pawlowska² and Janusz Blasiak ${ }^{3 凶}$ \\ 1Department of Maxillofacial Orthopedics and Orthodontics, Medical University of Wroclaw, Wrocław, Poland; 2Department of Orthodontics, \\ Medical University of Lodz, Łódź, Poland; 3Department of Molecular Genetics, University of Lodz, Łódź, Poland
}

Chronic myeloid leukemia $(\mathrm{CML})$ results from the $t(9 ; 22)$ reciprocal chromosomal translocation producing the $B C R-A B L 1$ gene, conferring growth and proliferation advantages in the CML cells. CML progresses from chronic, often syndrome-free, to blast phase, fatal if not treated. Although the involvement of BCR-ABL1 in some signaling pathways is considered as the cause of $\mathrm{CML}$, the mechanisms resulting in its progression are not completely known. However, BCR-ABL1 stimulates the production of reactive oxygen species (ROS), which levels increase with CML progression and induce BCR-ABL1 self-mutagenesis. Introducing imatinib and other tyrosine kinase inhibitors (TKIs) to CML therapy radically improved its outcome, but TKIs-resistance became an emerging problem. TKI resistance can be associated with even higher ROS production than in TKI-sensitive cells. Therefore, ROS-induced selfmutagenesis of BCR-ABL1 can be crucial for CML progression and TKI resistance and in this way should be taken into account in therapeutic strategies. As a continuous production of ROS by BCR-ABL1 would lead to its selfdestruction and death of CML cells, there must be mechanisms controlling this phenomenon. These can be dependent on DNA repair, which is modulated by BCR-ABL1 and can be different in CML stem and progenitor cells. Altogether, the mechanisms of the involvement of BCR$A B L 1$ in ROS signaling can be engaged in CML progression and TKI-resistance and warrant further study.

Key words: chronic myeloid leukemia, reactive oxygen species, DNA damage, DNA repair, cancer stem cells, imatinib resistance

Received: 18 July, 2016; revised: 20 September, 2016; accepted: 26 October, 2016; available on-line: 01 December, 2016

\footnotetext{
e-mail: jblasiak@biol.uni.lodz.pl
}

Abbreviations: AKT, protein kinase B; AP site, apurinic, apyrimidinic or abasic site; ATM, ataxia telangiectasia mutated; ATR, ataxia telangiectasia and Rad3 related; $B C R$, the breakpoint cluster region gene; $B C R-A B L 1$, fusion tyrosine kinase; BER, base excision repair; $c-A B L 1$, the Abelson proto-oncogene; CAT, catalase; CCR7, $\mathrm{C}-\mathrm{C}$ chemokine receptor type 7; CML, chronic myeloid leukemia; CSC, cancer stem cells; Cripto, a ligand for the GRP78 protein; DDR, DNA damage reaction; DNA-PK ${ }_{C S}$, DNA-dependent protein kinase, catalytic subunit; DSB, double-strand break; FANCC, Fanconi anemia complementation group $\mathrm{C}$; FOXO, forkhead box $\mathrm{O}$ transcription factor; G-CSF, granulocyte colony stimulating factor; GRP78, $78 \mathrm{kDa}$ glucose-regulated protein; HDACi, histone deacetylase inhibitor; HIF-1/2, hypoxia inducible factor-1/2; Hox-A9, homeobox protein; HSC, hematopoietic stem cell; ICAM-1, intercellular adhesion molecule 1; LT-HSC, long-term hematopoietic stem cell; MAPK, mitogen-activated protein kinases; Meis1, myeloid ecotropic viral integration site 1 homolog; PBX1, Pre-B-cell leukemia homeobox 1 ; PPAR $\gamma$, peroxisome proliferator-activated receptor- $\gamma ; \mathrm{Ph}$, Philadelphia chromosome; PI3K, phosphatidylinositol 3-OH kinase; PLK1, polo-like kinase 1; PTEN, phosphatase and tensin homolog; ROS, reactive oxygen species; SOD 1,2, superoxide dismutase 1,2; SSB, single-strand break; ST-HSC, short-term hematopoietic stem cell; TGF- $\beta$, transforming growth factor $\beta$; TKI, tyrosine kinase inhibitor; TLS, translesion synthesis; TNF- $\alpha$, tumor necrosis factor- $\alpha$

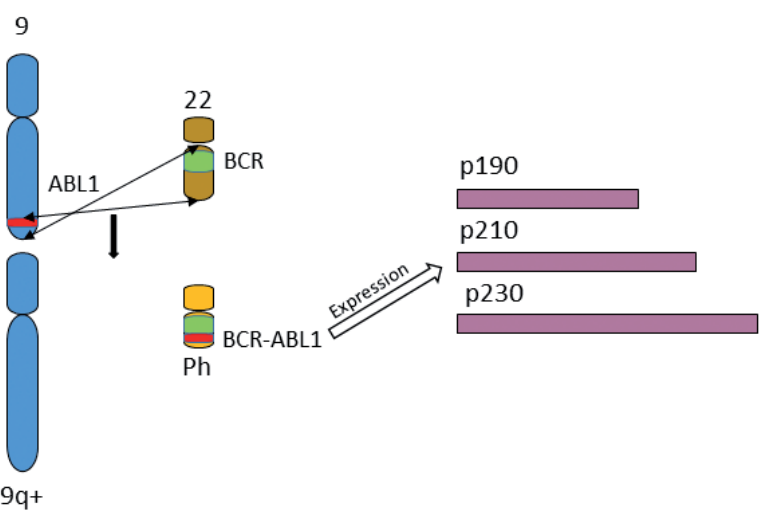

Figure 1. The $t(9 ; 22)$ chromosomal reciprocal translocation results in the Philadelphia (Ph) chromosome containing the BCRABL1 gene, which expression can give three protein products. The p210 protein displays the strongest oncogenic properties and can occur in two variants.

\section{INTRODUCTION}

Chronic myeloid leukemia (CML) is caused by the $\mathrm{t}(9 ; 22)$ chromosomal reciprocal translocation in hematopoietic stem cells, leading to the shortening of chromosome 22, which is called the Philadelphia chromosome $(\mathrm{Ph})$ and contains the BCR-ABL1 fusion gene (reviewed in Druker, 2008) (Fig. 1).

The product of this gene, the BCR-ABL1 protein, is a tyrosine kinase, which phosphorylates many downstream targets, including those important in cancer (Fig. 2).

Initially, the role of BCR-ABL1 in the transformation of bone marrow cells was attributed to conferring increased growth and proliferation to the transformed cells, but at present, an increased resistance to apoptosis is considered as the main effect induced by BCR-ABL1 in transforming cells (Leber, 2011).

Chronic myeloid leukemia is usually characterized by three consecutive phases. The chronic phase is usually symptom-free or is associated with mild symptoms, frequently disappearing upon the start of treatment, and can last for several years. In accelerated phase, an increase in the number of immature white blood cells in blood and bone marrow is observed. Some other changes in DNA, beside $\mathrm{Ph}$, can occur in this phase. Blast phase or blast crisis is fatal, if not treated, and patients in this phase display an uncontrolled increase in white blood cells and blasts population and additional genetic changes in blast cells. However, the disease can occur in only two phases as the accelerate phase may not follow. From the clinical point of view, it is obvious that CML can be diagnosed in blast phase, without any clinical evidence of preced- 


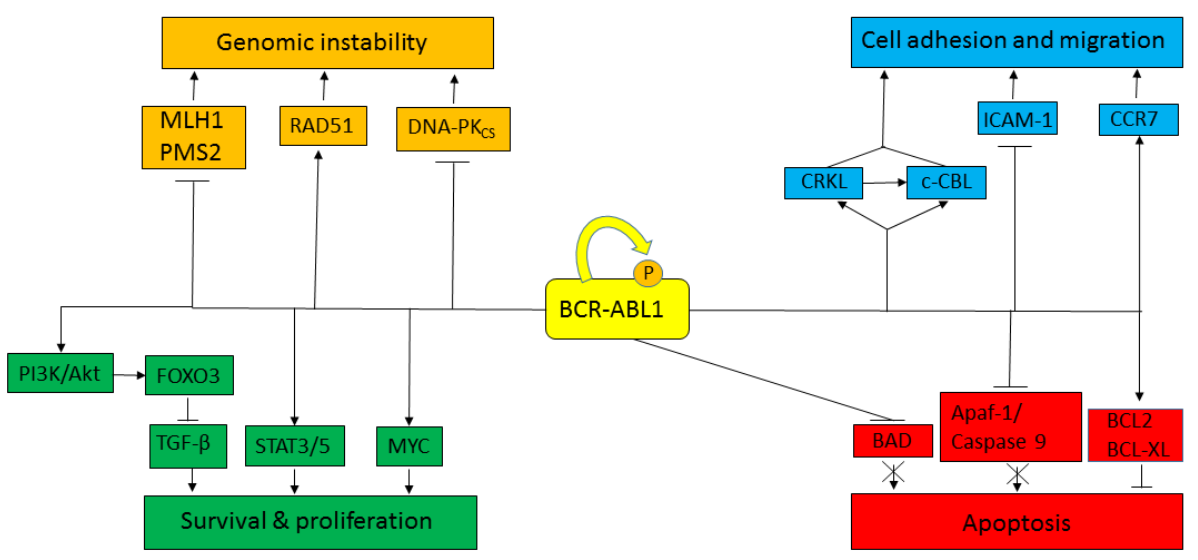

Figure 2. BCR-ABL1 is involved in cellular signaling pathways implicated in genomic instability, cell adhesion and migration, apoptosis, proliferation and survival, which all are important for cancer transformation supported by BCR-ABL1.

Presented are some pathways, covering only a small fraction of all possible interactions of BCR-ABL1. Moreover, whether the interaction leads to up- or downregulation of a particular protein can depend on the kind of cell or/and its environment. MLH1 and PMS2 are proteins of DNA mismatch repair, reducing errors of replication, RAD51 is a key protein for homologous recombination repair and DNA-PK CS $_{2}$ (DNA-dependent protein kinase, catalytic subunit) is involved in the repair of DNA double-strand breaks in non-homologous end joining pathway, which strongly influences genomic stability. CRKL, an adaptor protein, can mediate interaction between BCR-ABL1 and c-CBL, another adaptor, leading to defects in adhesion properties of the BCR-ABL1-positive cells. ICAM-1 (intercellular adhesion molecule 1) and CCR7 (C-C chemokine receptor type 7) are involved in cell migration and adhesion, which are defective in chronic myeloid leukemia cells. BCR-ABL1 can target the protein kinase Akt and FOXO3 (forkhead box 3), a transcription factor to hinder growth inhibition in response to TGF- $\beta$ (transforming growth factor $\beta$ ). Increased survival and proliferation can result also from the interaction of BCR-ABL1 with STATs (signal transducer and activator of transcription) and the MYC oncoprotein. BCR-ABL1 can interact with proteins directly involved in apoptosis, including BCL family proteins and caspases, making BCR-ABL1-positive cells resistant to apoptosis.

ing phases. Time needed for moving of CML from the chronic phase to the accelerated phase and then to the blast crisis, may be different for different patients and the mechanisms underlying this variability are not completely known. This can be due to the fact, that although mechanisms of CML induction can be attributed to the anti-apoptotic action of BCR-ABL1, molecular processes resulting in progression of the disease are largely unknown. They can however, be associated with genetic changes accumulated during the course of the disease (Deininger et al., 2000). They, in turn, induce and increase genomic instability, which is typical for almost all cancer cells. Reactive oxygen species (ROS) play an important role in the integrity of the genome, as they can damage DNA either directly or via their intermediates and increased ROS production is associated with BCRABL1 activity (Sattler et al., 2000).

The efficacy of CML therapy used to be low and a real breakthrough was the introduction of imatinib (imatinib mesylate, Gleevec, STI573), a tyrosine kinase inhibitor (TKI), which changed CML from a fatal disorder into a chronic disease. However, imatinib resistance soon became a budding problem, which was not definitely solved by the next generation of TKIs. TKI-resistance is observed in many cases of blast crisis (Perrotti et al., 2010). We and others showed that ROS can be important for imatinib resistance, which along with the accumulation of genetic changes in blast phase, suggest that ROS can play an important role in CML progression (Nieborowska-Skorska et al., 2011; NieborowskaSkorska et al., 2014; Slupianek et al., 2013; Koptyra et al., 2006). This role should be considered in a general involvement of ROS in cancer transformation.

\section{ROLE OF REACTIVE OXYGEN SPECIES IN GENOMIC STABILITY OF CANCER CELLS}

Reactive oxygen species are ubiquitous and play an important role in cellular signaling (Ray et al., 2012). How- ever, their excess, typical for oxidative stress, can have a devastating impact on cell functioning. An increased level of ROS was observed in many cancer cases, but in the majority of them the question whether they are the reason or a consequence of cancer is still open. As the solution of this problem can be crucial for cancer prevention, diagnosis and therapy, studies on the role of ROS in cancer are justified. Many aspects of ROS signaling can contribute to cancer induction and progression, but one of the most direct associations is through genomic instability observed in almost all cancer cells.

Genomic instability can be expressed as the extent of DNA mutations and chromosomal rearrangements in the genome. These changes are derived from DNA damages, but the source of them in cancer is not completely known. In certain cases, there is a causal relationship between the exposure to DNA-damaging environmental factors and cancer with the involvement of genomic instability, but in many circumstances such relationship is unknown. The extent of pre-mutagenic DNA lesions is regulated by the cellular DNA damage reaction (DDR) and DNA repair in particular (Zhou \& Elledge, 2000). Cancer-associated ROS can damage not only DNA, but also DNA repair proteins and other biomolecules important for DDR, leading to increased genomic instability. They can also damage enzymes of antioxidant defense, resulting in ROS accumulation.

Hydroxyl radical $\left({ }^{\bullet} \mathrm{OH}\right)$ is one of the most, if not the most, reactive ROS, which easily reacts with DNA by the addition to the C5-C6 double bond or abstraction of a proton from the methyl residue of thymine and $\mathrm{C}-\mathrm{H}$ bonds of the deoxyribose sugar (Cooke et al., 2003). These effects can lead to the production of a variety of purine and pyrimidine adduct radicals, which are reduced or oxidized in dependence on the environment (Steenken, 1997). The final products can show different pairing properties from the originals and contribute to DNA mutations during next cellular divisions. Transferring the electrons released by certain endo- and exogenous com- 
pounds to molecular oxygen, can lead to the formation of superoxide $\left(\mathrm{O}_{2}{ }^{-}\right)$, which can support ${ }^{\bullet} \mathrm{OH}$ production in the presence of iron ions (Nemmar et al., 2016). Oxidatively modified DNA bases can constitute a significant part of all the bases present in the cell (Cooke et al., 2003). Besides in situ formation of oxidatively modified DNA bases, they can be created by incorporation of a deoxynucleotide precursor, which was attacked by ROS and in fact, the majority of base modifications present in DNA can be produced in this way (Dumont et al., 2016).

The action of ROS can bring several other consequences for cellular DNA than point mutations resulted from non-canonical base-pair forming by oxidativelymodified bases. Such bases can constitute a block of the replication fork as replicative DNA polymerase cannot recognize a nucleotide precursor with a modified base and is not able to fit it into its catalytic pocket. Stalled polymerase can be replaced by a translesion synthesis (TLS) polymerase, which can be highly error-prone and induce mutations (Livneh et al., 2016). Otherwise, the replication fork can generate various DNA arrangements upon the encounter of certain modified bases, including chicken foot structures, which, when resolved, can produce DNA double-strand breaks (DSBs), which can result in chromosome breaks (Zhang et al., 2016). The formation of DNA single-strand breaks (SSBs) resulted from the restart of stalled replication fork is also possible.

ROS-induced the oxidatively modified DNA bases are primarily repaired by DNA base excision repair (BER). BER starts from recognizing a modified base by a DNA glycosylase, which removes the base by cleavage of the N-glycosylic bond between the base and 2'-deoxyribose. Such a base-free site (apurinic, apirimidinic or abasic site, AP site) is then cleaved either by a lyase activity of the glycosylase or a specialized AP endonuclease, which leads to a SSB (reviewed in Bellacosa \& Drohat, 2015). The termini of DNA at such SSB are then processed to become a substrate for DNA polymerase and DNA ligase. However, if the process of DNA repair synthesis is incomplete, which can be a consequence of several events, including ROS attack, a SSB will persist. Accumulation of SSBs formed in such way can result in DSBs and eventually chromosome breaks, if not repaired.

Therefore, ROS can induce a plethora of DNA damages, which in certain cases can be processed by overlapping DNA repair systems. If not repaired or misrepaired, they can result in DNA mutations or chromosomal breaks, which can induce genomic instability, a prerequisite to cancer transformation. A ROS-induced mutation can be casual for the transformation if occurs in a proto-oncogene or a gene encoding tumor suppressor. If such a mutation occurs in genes involved in DDR (DNA maintenance genes), it can result in further increase and accumulation of DNA lesions, increasing genomic instability and the chance that the DNA damage brings a mutation occurring in a gene important for malignant transformation.

\section{ROS SIGNALING IN HEMATOPOIETIC STEM CELLS}

As CML is a cancer stem cell-derived disease, ROS regulation in hematopoietic stem cells (HSCs) can play a role in its pathogenesis. Several signaling pathways are involved in ROS functioning in HSCs, including ATM (ataxia telangiectasia mutated), PI3K (phosphatidylinositol-3-OH kinase)/AKT (protein kinase B), PTEN (phosphatase and tensin homolog), MAPK (mitogen-activated protein kinases) and others (reviewed in Shi et al., 2012). In general, these pathways act to support the residence of HSCs in specific niches in hypoxia and a low ROS level (Fig. 3).

This issue is addressed in more detail in the next chapter.

Cytokines can play an important role in the interaction between HSCs and their niche, which was firstly demonstrated in association with telomere dysfunctionality (Schultz et al., 2016). Granulocyte colony-stimulating factor (G-CSF) was identified as involved in this interaction. However, G-CSF can stimulate ROS production in the PI3K/AKT pathway and these ROS can affect the function of HSCs, leading to their transformation (Zhu et al., 2006).

Reactive oxygen species are associated with inflammation, so it is justified to consider the influence of inflammation-related ROS on HSCs. The proinflammatory cytokine tumor necrosis factor- $\alpha(\mathrm{TNF}-\alpha)$ was reported to inhibit self-renewal of HSCs in Fanconi anemia complementation group C (FANCC) gene-deficient mice (Zhang et al., 2007). Fanconi anemia (FA) is a human disease characterized by genomic instability and excessive ROS production (Li et al., 2012). That TNF- $\alpha$-induced inhibition of mouse HSCs self-renewal was attributed to ROS accumulation as pretreatment with N-acetyl-Lcysteine (NAC), an antioxidant, reduced this effect.

The forkhead box O (FOXO) is a subfamily of mammalian transcription factors, which target many proteins in the PI3K-AKT/PKB signaling pathway (Ma and

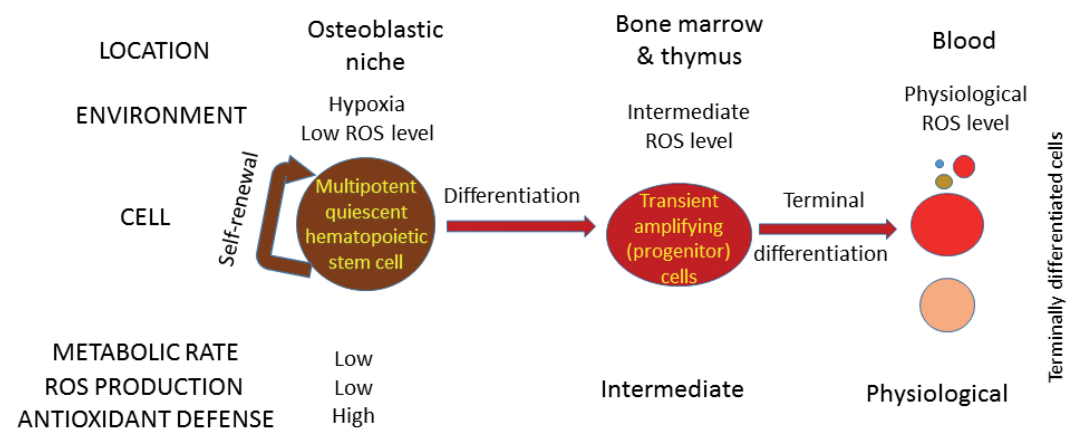

Figure 3. ROS affect hematopoiesis.

The formation of cellular components of blood is initiated by a multipotent hematopoietic stem cell (HSC) residing in an osteoblastic niche with low oxygen content. HSCs keep their metabolism at low level and produce low level of ROS, mostly neutralized by an effective antioxidant defense. HSCs replenish their population by self-renewal and occasionally differentiate to transit amplifying cells with various degree of potency and specifying different cell lineages. ROS can be involved in HSCs differentiation as well as terminal differentiation of transit amplifying cells. Oxidative stress associated with a high ROS level can induce HSCs senescence or death. 
Wang, 2012). These proteins include antioxidant enzymes, crucial for ROS neutralization, such as superoxide dismutases (SOD1 and 2) and catalase (CAT). The Foxo genes can play an important role in HSCs functioning and this role includes ROS regulation (Miyamoto et al., 2007; Tothova et al., 2007; Yamazaki et al., 2006).

ATM along with AKT and ataxia telangiectasia and Rad3 related (ATR), which are essential for maintaining genomic stability, can be involved in HSCs homeostasis, primarily in their self-renewal (Ito et al., 2006, Maryanovich et al., 2012). An upregulation of cyclin-depend-

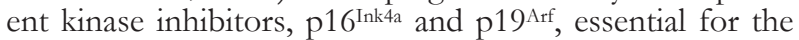
cell cycle regulation, was observed in HSCs of ATM-deficient mice when the level of ROS was increased. Similar effect was observed in HSCs of the Bmi-1-deficient mice, which suggests the involvement of epigenetic factors in ROS regulation of HSCs, as Bmi-1 is important for chromatin remodeling (Iwama et al., 2004; Lessard et al., 2003; Park et al., 2003).

The p38 MAPK is a protein encoded by gene responsive to stress stimuli, including UV radiation, osmotic and heat shocks (Alam et al., 2014). In fact it represents a class of proteins involved in important cellular functions, including differentiation, apoptosis and autophagy. It was shown that HSCs self-renewal strongly depended on normal control of ROS and functioning (Jang and Sharkis, 2007). The authors showed in that work two subpopulations of HSCs depending on their ROS intracellular content - ROS low $^{\text {and ROS }}{ }^{\text {high }}$, different in their long-term self-renewal ability. Moreover, a different level of expression of phosphorylated p38 MAPK was shown in ROShigh and ROSlow HSCs.

As genomic instability is a feature of almost all cancer cells it is reasonable to consider mechanisms of this effect in HSCs. However, DDR, which is crucial for genomic stability, in stem cells is not so well recognized as in their non-stem counterparts. Moreover, it is not easy to identify the most primitive CML stem cells, so the term "stem" would be rather used in operational sense, and not necessarily always as "the very first".

In general HSCs, as other stem cells, reside in a cellular compartment, called "niche", where they are protected from external insults. Therefore, the niche is not only a spatial structure, but also has a specific microenvironment. A majority of HSCs are in G0 phase of the cell cycle, allowing them to decrease the risk of mutations following DNA replication, but they are able to reenter the cycle to self-renew or differentiate to produce progenitor and terminally differentiated cells. This state is referred to as quiescence. Self-renewal occurs in the niche, whereas progenitor cells are produced outside of it.

Conditions in the HSCs niche should be precisely regulated to ensure proper functioning of the cells. Osteoblasts were identified as an important component of the HSCs niche in mice (osteoblastic niche) and it was shown that these cells were located in close proximity of vascular cells (vascular niche) (Kiel et al., 2005; He et al., 2016). Therefore, supporting HSCs by their various niches is crucial for maintaining their functions and it was shown that ROS could be involved in this effect (Jang \& Sharkis, 2007). However, this is not really surprising, because the niche should have a decreased level of ROS to avoid damage to HSC biomolecules. As ROS are produced from oxygen, decreasing the level of oxygen in the niche seems to be the most direct way to diminish ROS extent (Simsek et al., 2010). Other scenarios include increasing the activity of antioxidant enzymes, increasing the concentration of small antioxidants. The consequenc- es of ROS action on DNA of HSCs can be reversed, at least in part, by effective DNA repair system or in general, by increased DDR. These and other research suggest that keeping ROS at low level in HSCs depends on the interaction of the cells with their niche(s) (reviewed in Naka et al., 2008; Kiel et al., 2008).

As mentioned, DDR in stem cells can differ from that functioning in non-stem cells. Because HSCs are probably the best explored and known adult stem cells, DDR in these cells is relatively well known, but our knowledge on it is still incomplete and may not reflect general features of DDR in all kinds of stem cells. Moreover, DDR mechanisms can be different in different species. However, general DDR also can be species-specific, which is supported by repairadox - cells of rodents repair some DNA damage with lower efficacy than human cells, but both have similar ratio of survival (Hanawalt, 2001). The most important features of DDR in HSCs are underlined by the difference in DDR in quiescent and differentiating HSCs, which can be attributed to different proteins with overlapping functions in DNA repair and self-renewal or differentiation. This can be exemplified by the involvement of p53 in DDR and self-renewal in human HSCs (Milyavsky et al., 2010). The p53 protein is also considered as a mediator of HSCs "competition" for proper niche, which can be interpreted as a protective function of this protein in HSCs, independent of its role in DDR (Bondar \& Medzhitov, 2010). In general DDR in HSCs can be less effective and more error-prone than in nonstem counterparts, especially in quiescent cells (Rossi et al., 2007; Nijnik et al., 2007; Mohrin et al., 2010).

\section{ROS-DEPENDENT METABOLIC REGULATION OF HEMATOPOIETIC STEM CELLS IN THE HYPOXIC NICHE AND ITS ROLE IN LEUKEMOGENESIS}

The regulation of the metabolism of stem cells is essential for their stemness. It is not only due to the fundamental functions of these cells, but also due to their need of a proper environment. Metabolic processes are the source of many chemicals and physical particles, which can exert a detrimental effect on the cell. That is why stem cells keep their metabolism at a minimal required rate and are located in an environment with a low level of harmful insults. This functional-structural object is called stem-cell niche. In the case of HSCs, the niche is located in the endosteal regions of the bone marrow. The majority of HSCs in the niche is in a quiescent state limiting their activity to self-renewal. They are usually called long term HCSs (LT-HSCs) as they have a long-term self-renewal capacity after transplantation in a mouse foreign organ. However, the need for generating of billions and billions functional blood cells during the human lifetime, causes these LT-HSCs to increase their activity to produce progenitors, including short-term HSCs (ST-HSCs), lineage-restricted progenitors and terminally differentiated cells (Fig. 4).

Although the location of the stem cell niche implies some physical protection of the cells against physical and chemical detrimental agents, LT-HSCs acquires some unique properties, including distinctive DNA damage response (DDR), decreasing the chance of changes to their genome (Blanpain et al., 2011). However, DNA repair can be considered as a two-edged sword in HSCs for example DNA double-strand breaks in the niche are paired by non-homologous end joining, a DNA repair system, which is fast but error-prone and may lead to a leukemic transformation (Rossi et al., 2008; Pawlows- 


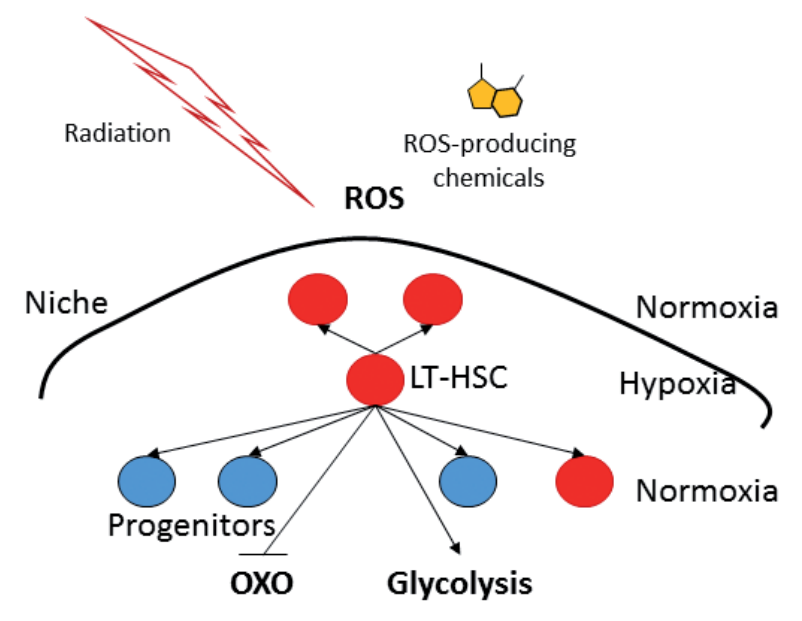

Figure 4. Long-term hematopoietic stem cells (LT-HSCs, red circles) reside in the bone marrow niche, a structure which shields the cells from detrimental external insults, including radiations and chemicals.

The metabolic activity of LT-HSCs is kept at minimum in the niche to avoid production of ROS and protect their DNA against detrimental factors. LT-HSCs essentially limit cellular division to self-renewal, but when needed they produce committed progenitor cells (blue circles), which can further differentiate. Hypoxia is typical for the niche to keep the ROS level low. HSCs in the niche preferentially use glycolysis as the source of energy than mitochondrial oxidative phosphorylation (OXO).

ka \& Blasiak, 2015). Detailed study of the HSCs niche revealed that the cells reside in a hypoxic environment, which is in agreement with general protective role of the niche, as the low partial pressure of oxygen results in a low level of ROS (Harrison et al., 2002). The consequences of hypoxic environment of the HSCs are not limited to their protection against detrimental action of ROS as hypoxia induces quiescence of these cells (Shima et al., 2010).

Although hypoxia can contribute to better protection of HSCs against environmental insults, it creates a serious problem for the metabolism of these cells. A reduced availability of $\mathrm{O}_{2}$ induces cellular and systemic response in many cells, including HSCs, and hypoxia inducible factor-1, HIF-1, plays a key role in this response (Semenza, 2010). This factor is responsible for quiescence of HSCs in hypoxia by forming heterodimers consisting of its two subunits, HIF-1 $\alpha$ and $\beta$, and by interaction with the $78 \mathrm{kDa}$ glucose-regulated protein, GRP78 and its ligand, Cripto (Miharada et al., 2012). As mitochondria are a rich source of ROS, HSCs display a low mitochondrial activity, which is associated with increased glycolysis (Wanet et al., 2015). Active switch from oxidative to glycolytic metabolism is mediated by HIF-1, through the conversion of puryvate into lactate by lactate dehydrogenase A (LDHA) or the process of puryvate decarboxylation, in which puryvate is converted into acetyl-CoA by the mitochondrial enzyme puryvate dehydrogenase. As the switch between oxidative phosphorylation and glycolysis in ATP production is typical for cancer cells, HSCs have prerequisites required for functioning as leukemic cells.

Recently, it was shown that HIF-1 $\alpha$, an oxygen-sensitive component of HIF-1, is transcriptionally activated by the homeobox protein Meis1 in human HPSCs (Kocabas et al., 2015). This interaction was mediated by the cofactors Pbx1 and HoxA9. It seems important in the context of HSPCs cancer transformation, as Meis1 was shown to be upregulated in acute leukemias (Kawagoe et al., 1999; Eppert et al., 2011; Becker \& Jordan, 2011). Moreover, both Pbx1 and HoxA9 also can be implicated in leukemogenesis (Nakamura et al., 1999; Aspland et al., 2001). Therefore, hypoxic environment in the HPSCs niche can contribute to leukemic transformation of these cells and mechanisms of HIF-1 regulation can be important for leukemogenesis and detailed studies are needed to assess the potential of interaction between HIF-1 and BCR-ABL1 as well as its components, BCR and ABL1. In general, there is a need to establish the relationship between metabolic characteristics of HSCs in hypoxic microenvironment and their association with fundamental properties of these cells including self-renewal, quiescence, apoptosis and cancer transformation (Zhang \& Sadek, 2014; Ryu et al., 2015; Testa et al., 2016).

To proliferate, HSCs activate the phosphatidylinositol 3-OH kinase (PI3K)/Akt/mTOR pathway with the involvement of growth factors and nutrients, including glucose (Yuan \& Cantley, 2008). This activation is associated with ROS production or decreased ROS scavenging. As ROS are required for normal cellular homeostasis, their activity should be strictly controlled. Several molecules including antioxidant enzymes, DDR proteins, polycomb proteins and others are involved in this control (Suda et al., 2011).

\section{BCR-ABL1 AND ROS PRODUCTION}

As we mentioned, elevated level of ROS can be associated with many cancers, but it is difficult to determine whether ROS belong to the reasons or consequences of the disease. It seems that both outcomes can occur in very many cases. If a cell is exposed to ROS, resulting in damage to a DNA repair gene, this will result in an increased chance of accumulating DNA damages upon the next cellular divisions, which can lead to genomic instability, increasing the probability of acquiring a mutation in cancer-related gene. DNA repair deficiency would result in a weaker control over intracellular ROS, leading to an elevated level of these species in cancer, despite the fact that the primary ROS, the reason of the cancer, are no longer present. This is a general scenario, but in certain cancers, the source of ROS can be attributed to some cancer-specific feature. This is the case in CML.

BCR-ABL1 was identified to stimulate ROS production in mouse-derived hematopoietic cells as this stimulation was blocked by imatinib (Sattler et al., 2000). Therefore, BCR-ABL1, the cause of CML, induces ROS production leading to oxidative stress, typical for many cancers. When this stress was induced by hydrogen peroxide in non-transformed hematopoietic cells, several events typical for BCR-ABL1-expressing cells occurred. Therefore, that important work suggests at least two crucial facts. Firstly, CML can be initiated by anti-apoptotic and proliferative signaling of BCR-ABL1, but the development of the disease can be related to oxidative stress induced by BCR-ABL1. Secondly, the progression of CML can be influenced by chemicals modulating ROS levels, including small-molecular weight antioxidants.

Kim and coworkers showed that the Tyr177 residue in the BCR-ABL1 protein was a major regulatory site in the ROS production pathway in BCR-ABL1-expressing cells (Kim et al., 2005). Two main mechanisms can be involved in enhanced ROS production by BCR-ABL1: increase in glucose metabolism and elevated activity of the electron transport chain in mitochondria (Kim et al., 
2005). The association between BCR-ABL1 and glucose pathway can be seen by the inhibition of glucose metabolism leading to a decreased level of protein phosphorylation. In general, the increase in ROS production in BCR-ABL1-positive cells can be dependent on the $\mathrm{PI} 3 \mathrm{~K} / \mathrm{mTOR}$ signaling pathway and PI3K activation itself was reported to be sufficient for ROS overproduction in BCR-ABL1-expressing cells. As PI3K is involved in glucose uptake and metabolism, these results confirm that glucose metabolism is important for ROS production by BCR-ABL1. These important results obtained by Kim et al., suggest possible mechanisms underlying mutual relationship between the activity of the BCR-ABL1 kinase and ROS production, which can be important for cancer biology and therapeutic targeting of the kinase in CML and other malignancies.

Increased ROS production stimulated by BCR-ABL1 can contribute to increased genomic instability in CML cells and this is sometimes interpreted as the consequence of the potential of BCR-ABL1 to induce genomic instability independently of its leukemogenic effect (reviewed in Quintas-Cardama \& Cortes, 2009). However, it should be taken into account that such conclusion is based on the recognition of cancer phenotype onset, which depends on the detection threshold of facilities to be used for this purpose. Moreover, this statement should be rather limited to the leukemia-onset effect, as genomic instability and associated mutagenesis can be attributed to CML progression.

Ilaria et al presented two mechanisms of increasing genomic instability by BCR-ABL1 (Ilaria et al., 2002). One of them assumed the involvement of BCR-ABL1 in DNA repair, which is supported by the evidence of the participation of normal c-ABL in DNA repair (Ilaria et al., 2002; Brain et al., 2001). However, c-ABL can be involved in DNA repair, but is not indispensable for this process (Matt and Hofmann, 2016). This issue will be discussed in more details in the next chapter. In their other explanation of the involvement of BCR-ABL1 in genomic instability, Ilaria et al., hypothesized that BCRABL1 can directly induce mutations at the level exceeding the repair capacity of the cell. In addition, an elevated expression of DNA polymerase $\beta$ was observed in BCR-ABL1-expressing cells (Troung et al., 2003; Canitrot et al., 1999).

The association between BCR-ABL1-stimulated ROS production and mutagenesis is sometimes considered as a feed-forward loop: BCR-ABL1 increases the extent of ROS, which, in turn, attack its gene, inducing mutations. Mutated $B C R-A B L 1$ produces more ROS, leading to self-mutagenesis and an increase in genomic instability. Therefore, this feed-forward loop can be rather seen as a vicious cycle leading to apoptosis of BCR-ABL1expressing cells. Because this is apparently not the case, there must be some control mechanisms of this self-mutagenesis and its influence on genomic stability. We and others showed that BCR-ABL1 could modulate DNA repair and this modulation was in many cases expressed as an increase in DNA repair efficacy, including efficacy of removing oxidative DNA damage (Slupianek et al., 2013; Muvarak et al., 2015; Nieborowska-Skorska et al., 2006; Somsedikova et al., 2014; Wang et al., 2014, Takagi et al., 2013; Brady et al., 2003). Therefore, the modulation of DNA repair by BCR-ABL1 can be associated with the control of ROS-induced self-mutagenesis to adjust it to such level, which would stimulate cancer transformation of CML cells, but below the threshold, which cannot be tolerated by the cell, leading to its apoptosis. This picture is additionally complicated by the fact that this extra DNA repair, stimulated by BCR-ABL1, can be unfaithful, leading to increased mutagenesis in BCRABL1-expressing cells, including the $B C R-A B L 1$ gene itself (Takagi et al., 2013; Brady et al., 2003). However, this represents rather a general conception and further studies are needed to shed light on this problem, which can be crucial for CML therapy in TKIs-resistant patients. Nevertheless, this seems to be an unsolved problem assuming that the CML cells population is homogenous. Therefore, a closer look should be taken at the intrinsic heterogeneity of CML cells.

\section{ROS IN CHRONIC MYELOID LEUKEMIA STEM CELLS}

Due to the cancer stem cells theory, cancer depends on a small population of "cancer stem cells (CSCs)", which are responsible for cancer maintenance, especially in unfavorable conditions for its development, e.g. when an anticancer drug is present in its immediate environment. It is commonly accepted that CSCs constitute the root of CML, but their precise identification and characterization have not been done yet (reviewed in: Zhou et al., 2015). It is accepted that CML cancer stem cells are within the $\mathrm{Lin}^{-} \mathrm{CD} 34^{+} \mathrm{CD} 38^{-}$population, whereas $\mathrm{CML}$ progenitor cells (CPCs) are characterized by the $\mathrm{Lin}^{-}$ $\mathrm{CD} 4^{+} \mathrm{CD} 38^{+}$phenotype. The former can be responsible for the initiation and maintenance of the disease, whereas the latter - for its progression. It is important that general therapeutic strategy in CML with TKIs targets only actively dividing cells and CSCs are often quiescent.

Skorski and his laboratory showed that both CSCs and CPSc in CML displayed high levels of ROS, independently of whether they were treated with TKIs or not Nieborowska-Skorska et al., 2012; Nieborowska-Skorska et al., 2013; Nieborowska-Skorska et al., 2014; Bolton-Gillespie et al., 2013). As mentioned above, PI3K is involved in increased ROS production
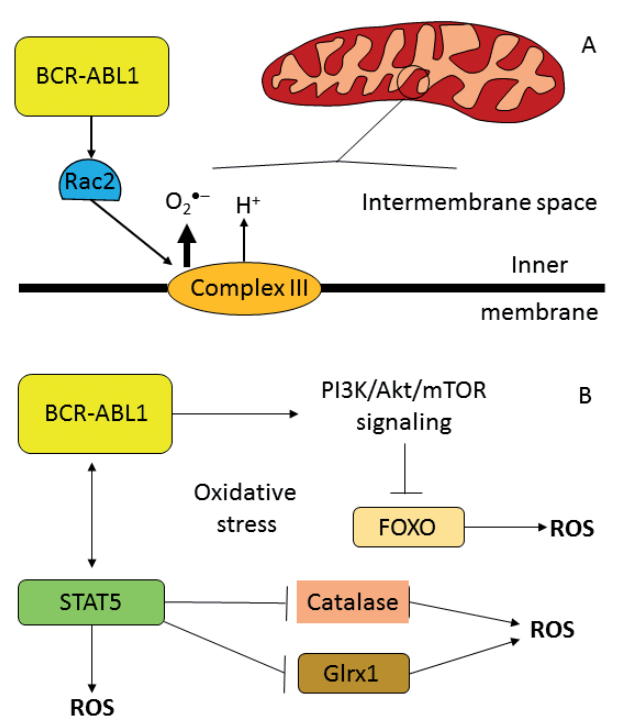

Figure 5. BCR-ABL1 interacts with the Rac2 GTPase and stimulates ROS production via the mitochondrial electron chain complex III (A). BCR-ABL1 can stimulate the Akt signaling pathway, which in turn inhibits forkhead O transcription factor (FOXO), essential for defense against oxidative stress (B).

In BCR-ABL1+ cells STAT5 transcriptionally regulates genes causing the enhanced ROS production. Prolonged stimulation of STAT5 by BCR-ABL1 downregulates two antioxidant enzymes: catalase and glutaredoxin-1 (GIrx1), which results in an enhanced level of ROS. 
in BCR-ABL1-expressing cells. Further research showed that RAC2, a PI3K effector, could be responsible for ROS increase in CSCs and CPCs by changing the electron flow through respiratory complex III (Nieborowska-Skorska, 2012) (Fig. 5).

Next, it was shown that the activation of the AKT protein, the key factor in DNA damage response signaling, could be inhibited in BCR-ABL1-expressing cells (Kim et al., 2005). Inhibition of AKT activation was observed in imatinib-treated CSCs and CPCs as compared with their imatinib-naive counterparts (Nieborowska-Skorska et al., 2014). Searching for the mechanisms of these changes led to unexpected conclusion that AKT regulated cellular reaction to oxidative DNA damage in CPCs, but not in CSCs. It is somehow surprising, as the AKT kinase plays the major role in DNA damage signaling also in stem cells and targeting this kinase is considered as a therapeutic strategy to eradicate the most primitive CSCs (Shimura et al., 2012).

\section{ROS IN CHRONIC MYELOID LEUKEMIA THERAPY WITH TYROSINE KINASE INHIBITORS}

Apart from the involvement of ROS in physiological cellular signaling, they can contribute to cancer transformation induced by oncogenic tyrosine kinases (Bourgeais et al., 2013). As mentioned above and shown in many studies, imatinib and other TKIs, decreased ROS level in BCR-ABL1-positive cells and this effect was underlined rather by the interaction of TKIs with the kinase, than TKIs scavenging effect or their interaction with cellular antioxidative system. Therefore, CML therapy with TKIs can be strengthened by the use of ROS scavengers. It was demonstrated that $\mathrm{N}$-acetyl cysteine, a ROS inhibitor, increased apoptosis induced by imatinib in BCR-ABL1-positive cells, both sensitive and resistant to this drug (Rakshit et al., 2009). This effect was associated with the production of nitric oxide mediated by endothelial nitric oxide synthase. However, these studies showed that glutathione, which is a ROS scavenger, partially decreased this effect, suggesting that the augmentation of the effect of imatinib by ROS inhibitors can result from different mechanism(s) than direct ROS scavenging.

Histone deacetylase inhibitors (HDACi), which induce more open structure of chromatin, enabling easier access of proteins involved in cell differentiation and death, were showed to potentiate BCR-ABL1-positive cells killing by KW-2449, a TKI targeting BCR-ABL1 and Src kinases, in both imatinib-sensitive and resistant cells (Nguyen et al., 2011). This effect was associated with an increased ROS production and enhanced extent of DNA double strand breaks, evaluated indirectly by H2AX phosphorylation. Similar results were obtained for a combined treatment of CML cells with another HDACi, vorinostat and BI2536, a PLK1 (polo-like kinase 1) (Dasmahapatra et al., 2013). The effect observed in that study was independent of the imatinib-sensitivity/refractory status of the cells.

These and other results indicate that ROS can contribute to killing BCR-ABL1-positive cells, possibly via the mechanisms associated with the increase in genomic stability to the level, which cannot be tolerated by the cell and leads to its death. These mechanisms can include several processes, including ROS-induced damage to cellular structures, DNA damage, interference with BCR-ABL1 pro-survival signaling pathways and DNA repair, as well as the modulation of cell cycle checkpoints, which in fact is involved in all these effects.
Therefore, ROS can play a dual role in the fate of CML cells: they can promote their genomic instability and accelerate CML progression associated with acquiring TKI resistance and resistance to apoptosis, but on the other hand they can contribute to CML cell killing. Therefore, there seems to be a subtle balance between pro- and anti-malignant effects of ROS in CML cells. Consequently, using ROS scavengers in combination with TKIs and other agents mediating CML cells elimination should be carefully planned to avoid unwanted effects.

In the light of BCR-ABL1-associated ROS production, imatinib-based CML therapy can be supplemented with chemicals that can inhibit the activity of antioxidant enzymes. The expression of a key enzyme of this system, SOD1, was reported to increase in CD34+ subpopulation of BCR-ABL-positive K562 cells as compared with the remaining, CD34-, subpopulation (Liu et al., 2011). Therefore, increased expression of this antioxidant enzyme could be attributed to leukemic CSCs, which are considered to be responsible for the disease relapse and imatinib resistance. Eradication of CSCs is the primary goal of CML therapy. It was observed that the knockdown of the SOD1 gene did not change the growth of the CD34+ BCR-ABL1-expressing cells, but sensitized them to imatinib (Liu et al., 2011). Interestingly, it was observed that NAC, a ROS scavenger, inhibited the proapoptotic effect of SOD1 knockdown, which suggested that increased SOD1 activity could be really associated with CML stem cells. NAC reversed also the inhibition of proliferation of CML cells evoked by oxidative DNA damage induced by a high level of ROS (Wu et al., 2015).

The balance between pro- and anti-carcinogenic effects of ROS in CML cells seems especially important in TKIs resistance, as imatinib-resistant cells displayed a higher level of ROS than their sensitive counterparts. We showed lastly that this result could be associated with mitochondria-mediated effects, including mitochondrial DNA damage, mitochondrial potential and expression of mitochondrial genes encoding proteins of the electron transport chain (Blasiak et al., 2016; Synowiec et al., 2015).

\section{CONCLUSIONS AND PERSPECTIVES}

BCR-ABL1 is the hallmark and cause of chronic myelogenous leukemia, conferring the advantage of growth and proliferation on CML cells. However, the progression of the disease may not necessarily be related directly to this fusion protein. Instead some effects associated with genomic instability, provoked by increased ROS production, can play an important role. That ROS overproduction can be related to BCR-ABL1 signaling. ROS produced by BCR-ABL1 can damage DNA, increasing genomic instability and promote BCR-ABL1 self-mutagenesis. However, there must be mechanisms preventing BCR-ABL1-directed cellular self-destruction. BCRABL1 can modulate DNA repair, but it can be an errorprone repair, contributing to BCR-ABL1 self-mutagenesis. Therefore, the balance between BCR-ABL1-induced ROS production and the extent of genomic instability is essential for survival of CML cells.

The problem of ROS-induced self-mutagenesis of BCR-ABL1 is directly associated with CML therapy. Imatinib and other TKIs, are effective in eliminating most of CML cells, but some of them survive TKIs treatment and cause CML relapse. They are CML stem cells, but their nature has not been known yet. The hierarchy of hematopoietic lineage is from hematopoietic 
stem cells, through transient amplifying cells and terminally differentiated cells found in blood, bone marrow, thymus and nervous tissue. Similarly, CML cells can contain a small subpopulation of cancer initiating cells, characterized by a high stem potential and responsible for the induction and maintenance of the disease and cancer progenitor cells, responsible for CML phenotype. It was suggested that some phenomena related to BCRABL1 mutagenesis, including the repair of ROS-induced oxidative DNA damage, can have different effects in CSCs and CPCs and this can contribute to "sustained" mutagenesis provoked by BCR-ABL1, supporting cancer transformation, but not leading to cell destruction. It is therefore tempting to supplement CML therapy with ROS-scavengers to inhibit BCR-ABL1 self-mutagenesis and decrease the level of genomic instability. However, increasing ROS level in BCR-ABL1 positive cells by several mechanisms, including the inhibition of the activity of antioxidant enzymes, can be effective in eradicating CML cells. Therefore, understanding the mechanism of DNA damage reaction in CML stem cells and their progenitors is crucial for the success of CML therapy.

It was shown that agonists of peroxisome proliferatoractivated receptor- $\gamma(\operatorname{PPAR} \gamma)$ represented by glitazones (antidiabetic drugs) decreased the population of LT CML stem cells of CML patients, whereas imatinib alone was not able to significantly reduce this population (Prost et al., 2015). The combination of pioglitazone with imatnib improved the results of the treatment. In searching of mechanisms underlying observed effects, it was shown that the activation of PPAR $\gamma$ was associated with downregulation of STAT5 and its two downstream targets, HIF- $2 \alpha$ and CITED2, which are essential for the stemness of LTHSCs (Du \& Jang, 2013; Wierenga et al., 2014). Residual CML patients treated temporarily with pioglitazone displayed sustained complete molecular response up to about 5 years after withdrawal of the drug. This seminal work confirmed the relevance of cancer therapy aimed at cancer stem cells. Another supporting evidence came from the results of recent work showing that perturbation of the p53 and c-MYC protein resulted in selective killing and differentiation of LT CML stem cells, while normal HSCs were unaffected (Abraham et al., 2016).

The identification of the most primitive CML stem cells is essential for the complete understanding of the pathogenesis of this disease and its therapy. However, as the most primitive cancer stem cell corresponding to a fertilized egg or embryonic stem cell could be rather a conception, than a real entity, current therapeutic strategies should be planned with taking into account intrinsic heterogeneity of CML cells population. This heterogeneity is also associated with different ROS production and their scavenging in CSCs and CPCs. This may create somehow puzzled situation, in which using particular antioxidant or ROS-inducer, can cause a reversed effects in this two kinds of cells. Therefore all clinical and molecular markers of CML should be analyzed at the same time to have a full picture of changes occurring after the treatment.

\section{Conflicts of interest}

The authors declare that there is no conflict of interest regarding this manuscript.

\section{REFERENCES}

Abraham SA, Hopcroft LE, Carrick E, Drotar ME, Dunn K, Williamson AJ, Korfi K, Baquero P, Park LE, Scott MT, Pellicano F,
Pierce A, Copland M, Nourse C, Grimmond SM, Vetrie D, Whetton AD, Holyoake TL (2016) Dual targeting of p53 and c-MYC selectively eliminates leukaemic stem cells. Nature 534: 341-346. doi: $10.1038 /$ nature18288

Alam MS, Gaida MM, Ogawa Y, Kolios AG, Lasitschka F, Ashwell JD (2014) Counter-regulation of $\mathrm{T}$ cell effector function by differentially activated p38. J Exp Med 211: 1257-1270. doi: 10.1084/ jem.20131917

Aspland SE, Bendall HH, Murre C (2001) The role of E2A-PBX1 in leukemogenesis. Oncogene 20: 5708-5717.Bellacosa A, Drohat AC (2015) Role of base excision repair in maintaining the genetic and epigenetic integrity of CpG sites. DNA Repair 32: 33-42. doi:10.1016/j.dnarep.2015.04.011

Becker MW, Jordan CT (2011) Leukemia stemness signatures step toward the clinic. Cell Stem Cell 9: 185-186. doi: 10.1016/j. stem.2011.08.006

Blanpain C, Mohrin M, Sotiropoulou PA, Passegue E (2011) DNAdamage response in tissue-specific and cancer stem cells. Cell Stem Cell 8: 16-29. DOI: 10.1016/j.stem.2010.12.012

Blasiak J, Hoser G, Bialkowska-Warzecha J, Pawlowska E, Skorski T (2016) Mitochondrial mutagenesis in BCR-ABL1-expressing cells sensitive and resistant to imatinib. Acta Biochim Pol 63: 365-370. doi: 10.18388/abp.2015_1189

Bolton-Gillespie E, Schemionek M, Klein HU, Flis S, Hoser G, Lange T, Nieborowska-Skorska M, Maier J, Kerstiens L, Koptyra M, Muller MC, Modi H, Stoklosa T, Seferynska I, Bhatia R, Holyoake TL, Koschmider S, Skorski T (2013) Genomic instability may originate from imatinib-refractory chronic myeloid leukemia cells. Blood 121: 4175-4183. doi: 10.1182/blood-2012-11-466938

Bondar T, Medzhitov R (2010) p53-mediated hematopoietic stem and progenitor cell competition. Cell Stem Cell 6: 309-322. doi: 10.1016/j.stem.2010.03.002

Bourgeais J, Gouilleux-Gruart V, Gouilleux F (2013) Oxidative metabolism in cancer. A STAT affair? JAKSTAT 2: e25764. doi: 10.4161/ jkst. 25764

Brady N, Gaymes TJ, Cheung M, Mufti GJ, Rassool FV (2003). Increased error-prone NHEJ activity in myeloid leukemias is associated with DNA damage at sites that recruit key nonhomologous end-joining proteins. Cancer Res 63: 1798-1805

Brain JM, Saksena A, Laneuville P (2001) The kinase inhibitor STI571 reverses the $\mathrm{Bcr} / \mathrm{Abl}$ induced point mutation frequencies observed in pre-leukemic P190Bcr/Abl transgenic mice. Lenkemia Res 26: 1011-1016

Burke BA, Carroll M (2010) BCR-ABL: a multi-faceted promoter of DNA mutation in chronic myelogeneous leukemia. Leukemia 24: 1105-1112. doi: 10.1038/leu.2010.67

Canitrot Y, Lautier D, Laurent G, Fréchet M, Ahmed A, Turhan AG, Salles B, Cazaux C, Hoffmann JS (1999) Mutator phenotype of BCR-ABL transfected $\mathrm{Ba} / \mathrm{F} 3$ cell lines and its association with enhanced expression of DNA polymerase beta. Oncogene 18: 2676-2680

Cooke MS, Evans MD, Dizdaroglu M, Lunec J (2003) Oxidative DNA damage: mechanisms, mutation, and disease. FASEB J 17: 11951214

Dumont E, Grüber R, Bignon E, Morell C, Aranda J, Ravanat JL, Tuñón I (2016) Singlet oxygen attack on guanine: reactivity and structural signature within the B-DNA helix. Chemistry 22: 12358-12362. doi: $10.1002 /$ chem.201601287

Dasmahapatra G, Patel H, Nguyen T, Attkisson E, Grant S (2013) PLK1 inhibitors synergistically potentiate HDAC inhibitor lethality in imatinib mesylate-sensitive or -resistant BCR/ABL+ leukemia cells in vitro and in vivo. Clin Cancer Res 15: 404-414. doi: 10.1158/1078-0432.CCR-12-2799

Deininger MW, Goldman JM, Melo JV (2000) The molecular biology of chronic myeloid leukemia. Blood 96: 3343-3356

Druker BJ (2008) Translation of the Philadelphia chromosome into therapy for CML. Blood 112: 4808-4817. doi: 10.1182/ blood-2008-07-077958

Du J, Yang YC (2013) Cited2 in hematopoietic stem cell function. Curr Opin Hematol 20: 301-307. doi: 10.1097/MOH.0b013e3283606022

Eppert K1, Takenaka K, Lechman ER, Waldron L, Nilsson B, van Galen P, Metzeler KH, Poeppl A, Ling V, Beyene J, Canty AJ, Danska JS, Bohlander SK, Buske C, Minden MD, Golub TR, Jurisica I, Ebert BL, Dick JE (2011) Stem cell gene expression programs influence clinical outcome in human leukemia. Nat Med 17: 10861093. doi: $10.1038 / \mathrm{nm} .2415$

Hanawalt PC (2001) Revisiting the rodent repairadox. Environ Mol Mutagen 38: 89-96

Harrison JS, Rameshwar P, Chang V, Bandari P (2002) Oxygen saturation in the bone marrow of healthy volunteers. Blood 99: 394

He Q, Swindle CS, Wan C, Flynn RJ, Oster RA, Chen D, Zhang F, Shu Y, Klug CA (2016) Enhanced hematopoietic stem cell self-renewal-promoting ability of clonal primary MSC versus their osteogenic progeny. Stem Cells Aug 2016. doi: 10.1002/stem.2481

Ilaria RL (2002) Bcr/Abl, leukemogenesis, and genomic instability: a complex partnership. Leuk Res 26: 971-973 
Ito K, Hirao A, Arai F, Takubo T, Matsuoka S, Miyamoto K, Ohmura M, Naka K, Hosokawa Y, Ikeda M, Suda T (2006) Reactive oxygen species act through p38 MAPK to limit the lifespan of hematopoietic stem cells. Nat Med 12: 446-451

Iwama A, Oguro H, Negishi M, Kato W, Morita Y, Tsukui H, Ema H, Kamijo T, Katoh-Fukui Y, Koseki H, van Lohuizen M, Nakauchi $\mathrm{H}$ (2004) Enhanced self-renewal of hematopoietic stem cells mediated by the polycomb gene product Bmi-1. Immunity 21: 843-851

Jang YY, Sharkis SJ (2007) A low level of reactive oxygen species selects for primitive hematopoietic stem cells that may reside in the low-oxygenic niche. Blood 110: 3056-3063

Kawagoe H, Humphries RK, Blair A, Sutherland HJ, Hogge DE (1999) Expression of HOX genes, HOX cofactors, and MLL in phenotypically and functionally defined subpopulations of leukemic and normal human hematopoietic cells. Leukemia 13: 687-698

Kiel MJ, Morrison SJ (2008) Uncertainty in the niches that maintain haematopoietic stem cells. Nat Rev Immunol 8: 290-301. doi: $10.1038 /$ nri2279

Kiel MJ, Yilmaz OH, Iwashita T, Terhorst C, Morrison SJ (2005) SLAM family receptors distinguish hematopoietic stem and progenitor cells and reveal endothelial niches for stem cells. Cell 121: 1109-1121

Kim JH, Chu SC, Gramlich JL, Pride YB, Babendreier E, Chauhan D, Salgia R, Podar K, Griffin JD, Sattler M (2005) Activation of the $\mathrm{PI} 3 \mathrm{~K} / \mathrm{mTOR}$ pathway by BCR-ABL contributes to increased production of reactive oxygen species. Blood 105: 1717-1723

Kim YJ, Wilson DM (2012) Overview of base excision repair biochemistry. Curr Mol Pharmacol 5: 3-13

Kocabas F, Xie L, Xie J, Yu Z, DeBerardinis RJ, Kimura W, Thet S, Elshamy AF, Abouellail H, Muralidhar S, Liu X, Chen C, Sadek HA, Zhang CC, Zheng J (2015) Hypoxic metabolism in human hematopoietic stem cells. Cell Biosci 39. doi: 10.1186/s13578-015-00203

Koptyra M, Falinski R, Nowicki MO, Stoklosa T, Majsterek I, Nieborowska-Skorska M, Blasiak J, Skorski T (2006) BCR/ABL kinase induces self-mutagenesis via reactive oxygen species to encode imatinib resistance. Blood 108: 319-327

Leber B (2011) CML biology for the clinican in 2011: six impossible things to believe before breakfast on the way to cure. Curr Oncol 18m: e185-e190

Lessard J, Sauvageau G (2003) Bmi-1 determines the proliferative capacity of normal and leukaemic stem cells. Nature 423: 255-260

Li J, Sipple J, Maynard S, Mehta PA, Rose SR, Davies SM, Pang, Q (2012) Fanconi anemia links reactive oxygen species to insulin resistance and obesity. Antioxid Redox Signal 17: 1083-1098. doi: 10.1089 /ars.2011.4417

Liu L, Chen R, Huang S, Wu Y, Li G, Liu Q, Yin D, Liang Y (2011) Knockdown of SOD1 sensitizes the CD34+ CML cells to imatinib therapy. Med Oncol 28: 835-839. doi: 10.1007/s12032-010-9529-9

Livneh Z, Cohen IS, Paz-Elizur T, Davidovsky D, Carmi D, Swain U, Mirlas-Neisberg N (2016) How do DNA polymerases switch during translesion DNA synthesis? DNA Repair 44: 59-67

Ma Y, Wang H (2012) PI3K/Akt/FoxO: a novel participant in signal transduction in bone cells under mechanical stimulation. Cell Biol Int 36: 923-926. doi: 10.1042/CBI20120078

Matt S, Hofmann TG (2016) The DNA damage-induced cell death response: a roadmap to kill cancer cells. Cell Mol Life Sci 73: 2829_ 2850

Maryanovich M, Oberkovitz G, Niv H, Vorobiyov L, Zaltsman Y, Brenner O, Lapidot T, Jung S, Gross A (2012) The ATM-BID pathway regulates quiescence and survival of haematopoietic stem cells. Nat Cell Biol 14: 535-541

Miharada K, Karlsson G, Rehn M, Rörby E, Siva K, Cammenga J, Karlsson S (2012) Hematopoietic stem cells are regulated by Cripto, as an intermediary of HIF-1 in the hypoxic bone marrow niche. Ann N Y Acad Sci 1266: 55-62. doi: 10.1111/j.1749-6632.2012.06564.x

Milyavsky M, Gan OI, Trottier M, Komosa M, Tabach O, Notta F, Lechman E, Hermans KG, Eppert K, Konovalova Z, Ornatsky O, Domany E, Meyn MS, Dick JE (2010) A distinctive DNA damage response in human hematopoietic stem cells reveals an apoptosisindependent role for p53 in self-renewal. Cell Stem Cell 7: 186-197. doi: 10.1016/j.stem.2010.05.016

Miyamoto K, Araki KY, Naka K, Arai F, Takubo K, Yamazaki S, Matsuoka S, Miyamoto T, Ito K, Ohmura M, Chen C, Hosokawa K, Nakauchi H, Nakayama K, Nakayama KI, Harada M, Motoyama N, Suda T, Hirao A (2007) Foxo3a is essential for maintenance of the hematopoietic stem cell pool. Cell Stem Cell 1: 101-112. doi: 10.1016/j.stem.2007.02.001

Mohrin M, Bourke E, Alexander D, Warr MR, Barry-Holson K, Le Beau MM, Morrison CG, Passegué E (2010) Hematopoietic stem cell quiescence promotes error-prone DNA repair and mutagenesis. Cell Stem Cell 7: 174-185. doi: 10.1016/j.stem.2010.06.014

Muvarak N, Kelley S, Robert C, Baer MR, Perrotti D, Gambacorti-Passerini C, Civin C, Scheibner K, Rassool FV (2015). c-myc generates repair errors via increased transcription of alternative-NHEJ factors,
Lig3 and PARP1, in tyrosine kinase-activated leukemias. Mol Cancer Res 13: 699-712. doi: 10.1158/1541-7786.MCR-14-0422

Naka K, Muraguchi T, Hoshii T, Hirao A (2008) Regulation of reactive oxygen species and genomic stability in hematopoietic stem cells. Antioxid Redox Signal 10: 1883-1894. doi: 10.1089/ars.2008.2114

Nakamura T, Yamazaki Y, Hatano Y, Miura I (1999) NUP98 is fused to PMX1 homeobox gene in human acute myelogenous leukemia with chromosome translocation $\mathrm{t}(1 ; 11)(\mathrm{q} 23 ; \mathrm{p} 15)$. Blood 94: 741-747

Nemmar A, Beegam S, Yuvaraju P, Yasin J, Tariq S, Attoub S, Ali $\mathrm{BH}$ (2016) Ultrasmall superparamagnetic iron oxide nanoparticles acutely promote thrombosis and cardiac oxidative stress and DNA damage in mice. Part Fibre Toxicol 13: 22. doi: 10.1186/s12989-0160132-x

Nguyen T, Dai Y, Attkisson E, Kramer L, Jordan N, Nguyen N, Kolluri N, Muschen M, Grant S (2011) HDAC inhibitors potentiate the activity of the BCR/ABL kinase inhibitor KW-2449 in imatinib-sensitive or -resistant BCR/ABL+ leukemia cells in vitro and in vivo. Clin Cancer Res 17: 3219-3232. doi: 10.1158/1078-0432.CCR-11-0234

Nieborowska-Skorska M, Flis S, Skorski T (2014) AKT-induced reactive oxygen species generate imatinib-resistant clones emerging from chronic myeloid leukemia progenitor cells. Leukemia 28: 2416-2418. doi: 10.1038/leu.2014.249

Nieborowska-Skorska M, Hoser G, Hochhaus A, Stoklosa T, Skorski T (2013) Anti-oxidant vitamin $E$ prevents accumulation of imatinib-resistant BCR-ABL1 kinase mutations in CML-CP xenografts in NSG mice. Leukemia 27: 2253-2254. doi: 10.1038/leu.2013.123

Nieborowska-Skorska M, Kopinski PK, Ray R, Hoser G, Ngaba D, Flis S, Cramer K, Reddy M.M, Koptyra M, Penserga T, Glodkowska-Mrowka E, Bolton E, Holyoake TL, Eaves CJ, Cerny-Reiterer S, Valent P, Hochhaus A, Hughes TP, van der Kuip H, Sattler M, Wiktor-Jedrzejczak W, Richardson C, Dorrance A, Stoklosa T, Williams DA, Skorski T (2012) Rac2-MRC-cIII-generated ROS cause genomic instability in chronic myeloid leukemia stem cells and primitive progenitors. Blood 119: 4253-4263. doi: 10.1182/ blood-2011-10-385658

Nieborowska-Skorska M, Stoklosa T, Datta M, Czechowska A, Rink L, Słupianek A, Koptyra M, Seferyncka I, Krszyna K, Blasiak J, Skorski T (2006) ATR-Chk1 axis protects BCR/ABL leukemia cells from the lethal effect of DNA double-strand breaks. Cell Cycle 5: 994-1000

Nijnik A, Woodbine L, Marchetti C, Dawson S, Lambe T, Liu C, Rodrigues NP, Crockford TL, Cabuy E, Vindigni A, Enver T, Bell JI, Slijepcevic P, Goodnow CC, Jeggo, PA, Cornall RJ (2007) DNA repair is limiting for haematopoietic stem cells during ageing. Nature 447: 686-690

Park IK, Qian D, Kiel M, Becker MW, Pihalja M, Weissman IL, Morrison SJ, Clarke MF (2003) Bmi-1 is required for maintenance of adult self-renewing haematopoietic stem cells. Nature 423: 302-305

Pawlowska E, Blasiak J (2015) DNA repair - a double-edged sword in the genomic stability of cancer cells - the case of chronic myeloid leukemia. Int J Mol Sci 16: 27535-27549. doi: 10.3390/ ijms161126049

Perrotti D, Jamieson C, Goldman J, Skorski T (2010) Chronic myeloid leukemia: mechanism of blastic transformation. I Clin Invest 120: 2254-2264. doi: 10.1172/JCI41246

Prost S, Relouzat F, Spentchian M, Ouzegdouh Y, Saliba J, Massonnet G, Beressi JP, Verhoeyen E, Raggueneau V, Maneglier B, Castaigne S, Chomienne C, Chrétien S, Rousselot P, Leboulch P (2015) Erosion of the chronic myeloid leukaemia stem cell pool by PPAR $\gamma$ agonists. Nature 525: 380-383. doi: 10.1038/nature15248

Quintas-Cardama A, Cortes J (2009) Molecular biology of bovr-abl1 positive chronic myeloid leukemia. Blood 113: 1619-1630

Rakshit S, Bagchi J, Mandal L, Paul K, Ganguly D, Bhattacharjee S, Ghosh M, Biswas N, Chaudhuri U, Bandyopadhyay S (2009) Nacetyl cysteine enhances imatinib-induced apoptosis of $\mathrm{Bcr}-\mathrm{Abl}+$ cells by endothelial nitric oxide synthase-mediated production of nitric oxide. Apoptosis 14: 298-308. doi: 10.1007/s10495-008-0305-7

Ray PD, Huang BW, Tsuji Y (2012) Reactive oxygen species (ROS) homeostasis and redox regulation in cellular signaling. Cell Signal 24: 981-990. doi: 10.1016/j.cellsig.2012.01.008

Rossi DJ, Bryder D, Seita J, Nussenzweig A, Hoeijmakers J, Weissman IL (2007) Deficiencies in DNA damage repair limit the function of haematopoietic stem cells with age. Nature 447: 725-729

Rossi DJ, Jamieson CH, Weissman IL (2008) Stem cells and the pathways to aging and cancer. Cell 132: 681-696. DOI: 10.1016/j. cell.2008.01.036

Ryu JM, Lee HJ, Jung YH, Lee KH, Kim DI, Kim JY, Ko SH, Choi GE, Chai II, Song EJ, Oh JY, Lee SJ, Han HJ (2015) Regulation of stem cell fate by ROS-mediated alteration of metabolism. Int I Stem Cells 8: 24-35. doi: 10.15283/ijsc.2015.8.1.24

Sattler M, Verma S, Shrikhande G, Byrne CH, Pride YB, Winkler T, Greenfield EA, Salgia R, Griffin JD (2000) The BCR/ABL tyrosine kinase induces production of reactive oxygen species in hematopoietic cells. J Biol Chem 275: 24273-24278 
Schultz MB, Sinclair DA (2016) When stem cells grow old: phenotypes and mechanisms of stem cell aging. Development 143: 3-14. doi: 10.1242/dev.130633

Semenza GL (2009) Regulation of cancer cell metabolism by hypoxiainducible factor 1. Semin Cancer Biol 19: 12-16. doi: 10.1016/j.semcancer.2008.11.009

Shi X, Zhang Y, Zheng J, Pan J (2012) Reactive oxygen species in cancer stem cells. Antioxid Redox Signal 343: 429-434. doi: 10.1089/ ars.2012.4529

Shima H, Takubo K, Tago N, Iwasaki H, Arai F, Takahashi T, Suda T (2010) Acquisition of G0 state by CD34-positive cord blood cells after bone marrow transplantation. Exp Hematol 38: 1231-1240. DOI: 10.1016/j.exphem.2010.08.004

Shimura T, Noma N, Oikawa T, Ochia Y, Kakuda S, Kuwahara Y, Takai Y, Takahashi A, Fukumoto M (2012) Activation of the AKT/ cyclin D1/Cdk4 survival signaling pathway in radioresistant cancer stem cells. Oncogenesis 1: e12. doi: 10.1038/oncsis.2012.12

Simsek T, Kocabas F, Zheng J, Deberardinis RJ, Mahmoud AI, Olson EN, Schneider JW, Zhang CC, Sadek HA (2010) The distinct metabolic profile of hematopoietic stem cells reflects their location in a hypoxic niche. Cell Stem Cell 7: 380-390. doi: 10.1016/j. stem.2010.07.011

Slupianek A, Falinski R, Znojek P, Stoklosa T, Flis S, Doneddu V, Pytel D, Synowiec E, Blasiak J, Bellacosa A, Skorski T (2013) BCRABL1 kinase inhibits uracil DNA glycosylase UNG2 to enhance oxidative DNA damage and stimulate genomic instability. Leukemia 27: 629-634. doi: 10.1038/leu.2012.294

Somsedikova A, Markova E, Kolenova A, Puskacova J, Kubes M, Belyaev I (2014) Constitutive 53BP $1 / \gamma \mathrm{H} 2 \mathrm{AX}$ foci are increased in cells of ALL patients dependent on BCR-ABL and TEL-AML1 preleukemic gene fusions. Neoplasma 61: 617-625

Suda T, Takubo K, Semenza GL (2011) Metabolic regulation of hematopoietic stem cells in the hypoxic niche. Cell Stem Cell 9: 298310. doi: 10.1016/j.stem.2011.09.010

Synowiec E, Hoser G, Bialkowska-Warzecha J, Pawlowska E, Skorski T, Blasiak J (2015) Doxorubicin differentially induces apoptosis, expression of mitochondrial apoptosis-related genes, and mitochondrial potential in BCR-ABL1-expressing cells sensitive and resistant to imatinib. Biomed Res Int 2015: 673512. doi: 10.1155/2015/673512

Takagi M, Sato M, Piao J, Miyamoto S, Isoda T, Kitagawa M, Honda H, Mizutani S (2013) ATM-dependent DNA damage-response pathway as a determinant in chronic myelogenous leukemia. DNA Repair 12: 500-507. doi: 10.1016/j.dnarep.2013.04.022

Testa U, Labbaye C, Castelli G, Pelosi E (2016) Oxidative stress and hypoxia in normal and leukemic stem cells. Exp Hematol 44: 540560. doi: 10.1016/j.exphem.2016.04.012

Tothova Z, Kollipara R, Huntly BJ, Lee BH, Castrillon DH, Cullen DE, McDowell EP, Lazo-Kallanian S, Williams IR, Sears C, Armstrong SA, Passegue ER, DePinho A, Gilliland DJ (2007) FoxOs are critical mediators of hematopoietic stem cell resistance to physiologic oxidative stress. Cell 128: 325-339

Truong T, Sun G, Doorly M, Wang JY, Schwartz MA (2003) Modulation of DNA damage-induced apoptosis by cell adhesion is independently mediated by p53 and c-Abl. Proc Natl Acad Sci USA 100: 10281-10286

Wanet A, Arnould T, Najimi M, Renard P (2015) Connecting mitochondria, metabolism, and stem cell fate. Stem Cells Dev 24: 19571971. doi: $10.1089 /$ scd.2015.0117

Wang Z, Liu Z, Wu X, Chu S, Wang J, Yuan H, Roth M, Yuan YC, Bhatia R, Chen W (2014) ATRA-induced cellular differentiation and CD38 expression inhibits acquisition of BCR-ABL mutations for CML acquired resistance. PLoS Genet 10: e1004414. doi: 10.1371/ journal.pgen.1004414

Wierenga AT, Vellenga E, Schuringa JJ (2014) Convergence of hypoxia and TGF $\beta$ pathways on cell cycle regulation in human hematopoietic stem/progenitor cells. PLoS One 31: e93494. doi: 10.1371/journal. pone.0093494. eCollection 2014

Wu L, Chen X, Huang L, Tian J, Ke F, Xu J, Chen Y, Zheng M (2015) A novobiocin derivative, XN4, inhibits the proliferation of chronic myeloid leukemia cells by inducing oxidative DNA damage. PLoS One 10: e0123314. doi: 10.1371/journal.pone.0123314

Yamazaki S, Iwama A, Takayanagi S, Morita Y, Eto K, Ema H, Nakauchi H (2006) Cytokine signals modulated via lipid rafts mimic niche signals and induce hibernation in hematopoietic stem cells. EMBO J 25: 3515-3523

Yuan TL, Cantley LC (2008) PI3K pathway alterations in cancer: vari-ations on a theme. Oncogene 27: 5497-5510. doi: 10.1038/ onc. 2008.245

Zhang CC, Sadek HA (2014) Hypoxia and metabolic properties of hematopoietic stem cells. Antioxid Redox Signal 20: 1891-1901. doi: 10.1089/ars.2012.5019

Zhang J, Dai Q, Park D, Deng X (2016) Targeting DNA replication stress for cancer therapy. Genes 7: E51. doi: 10.3390/genes7080051

Zhang X, Sejas DP, Qiu Y, Williams DA, Pang Q (2007) Inflammatory ROS promote and cooperate with the Fanconi anemia mutation for hematopoietic senescence. J Cell Sci 120: 1572-1583

Zhou BB, Elledge SJ (2000) The DNA damage response: putting checkpoints in perspective. Nature 408: 433-439. doi: $10.1038 / 35044005$

Zhou H, Xu R (2015) Leukemia stem cells: the root of chronic myeloid leukemia. Protein Cell 6: 403-412. doi: 10.1007/s13238-0150143-7

Zhu Q, Xia S.L, Mills GB, Lowell CA, Touw IP, Corey SJ (2006) GCSF induced reactive oxygen species involves Lyn-PI3-kinase-Akt and contributes to myeloid cell growth. Blood 107: 1847-1856 